\title{
The requirements of forestry cooperative organization development in China: a case study of different stakeholder groups
}

\author{
Jing Wu, Feng Han, Yang Gao and Yali Wen*
}

\begin{abstract}
Wu, J., Han, F., Gao, Y., Wen, Y. 2013. The requirements of forestry cooperative organization development in China: a case study of different stakeholder groups. Forestry Studies | Metsanduslikud Uurimused 59, 59-69. ISSN 1406-9954.

Abstract. After China's collective forest tenure reform, cooperation organization has played an important role on the development of community forestry. In order to analyse the different stakeholders' opinion and suggestion on the development of forestry cooperation organization, publicizing and training, participatory interview, brainstorming, and questionnaire surveys were used in this case study. According to the results it can be seen that the real motivation for the development of cooperatives is farmers' demands and the demands come from farmers' pursuit of interests in forest industry. Cooperatives in China are still in the early stage of development, and the cooperative laws cannot cover all the basic features of the forestry and the cooperatives. Therefore, the relevant laws and guarantee systems for resource exploitation and management, publicity and demonstration, forestry technology training as well as the preferential policies such as tax breaks, are needed for the sound development of China's forestry cooperation organization.
\end{abstract}

Keywords: forestry cooperation organization, case study, stakeholders, China.

Author's address: School of Economics and Management, Beijing Forestry University, 100083, 35 Tsinghua East Road, Beijing, China, *e-mail: wenyali2003@163.com

\section{Introduction}

In the 1970s, China launched a reform of its rural economic system, moving towards a "household contract responsibility system," which aroused great enthusiasm for production among farmers and boosted the development of agricultural productivity. However, owing to the asymmetry of market information; the small scale of management (Xie \& Li, 2010); and the shortage of capital, labor, technology and other factors of production, households remained in a disadvantaged competitive position in the farm products market. To improve households' market competitiveness, a variety of specialized farmer cooperatives have come into being since the mid-1980s (Zhang \&
Zhang, 2009). Since the issue of the Law of the People's Republic of China on Specialized Farmer Cooperatives in July 2007, cooperatives have been expected to play a larger role in the development of China's rural areas and addressing issues concerning agriculture, the countryside, and farmers (Nie, 1995).

After China's collective forest tenure reform, the verification of forest ownership clarified the subjects of forest management, resulting in an unprecedented increase in the number of subjects and a rapid decline in the scale of forest production and management (Zhan, 2010), leading to the fragmentation of foresters' production and management objectives. Since the implementation of collective forest tenure re- 
form, collective forests have been allotted to tens of thousands of households, causing a dispersion of the management area, a drop in farmers' ability to withstand risks, and an increase in forest management costs, which is adverse to the formation of scaled forest management and the effective allocation of resources. How to enable forest farmers to be more competitive in the forest products market and raise their income from forestry, and how to improve the efficiency of collective forest resource allocation, have become real and urgent problems for China's forestry development. Confronted with this new situation and new problems after the collective forest tenure reform, especially in response to the needs of tens of thousands of households and the marketization of forestry development, forest farmers formed cooperatives. Currently, forest cooperative organizations in the southern collective forest area are enjoying rapid development, and forest farmers have increasing requirements for these cooperatives (Zhang \& Zhi, 2010). Under these circumstance, the government needs to provide forest farmers with scientific guidance to help them understand, establish, and operate cooperatives successfully.

The main aims of this study are to analyze the different stakeholders of collective forest management, especially forestry cooperative organization members; to recognize major problems existing in the development of cooperative organizations since the collective forest rights reform; improve the sustainable management and operation of collective forests; and collect the suggestions and opinions of the members of forest farmer cooperation organizations, villagers, county forestry departments, and forestry institutions for better development of forestry cooperative organizations.

\section{Material and Methods}

\section{Study area}

\section{General introduction to Youxi County in Fujian Province}

Youxi County is located in the center of Fujian Province in China; it has abundant forest resources (Figure 1). It is one of the 48 key counties in the collective forest areas of Southern China, and more than $80 \%$ of its mountain forest is collective. It had 121 forestry associations (including branches) of all varieties and 46 forestry cooperatives as of 2011. Youxi County is listed as a project county for forestry reform by the Food and Agriculture Organization, and China's State Forestry Administration (SFA) designated it as a demonstration county for the first established forest farmer cooperatives in 2011.

\section{Social and economic situations of case villages}

Shanlian Village is located at the northwestern part of Xicheng Town, Youxi County of Fujian Province. There are 3 administrative villages of it, 10 villager groups, 210 families and 930 persons. The total area of land is $0.735 \mathrm{ha}(11.020 \mathrm{Mu})$ and $0.625 \mathrm{ha}(9.379$ $\mathrm{Mu}$ ) of which is for forestry. The amount of forest land is $0.562 \mathrm{ha}(8.434 \mathrm{Mu})$, and 0.667 ha $(10 \mathrm{Mu})$ per capita. There are 0.161 ha $(2.422 \mathrm{Mu})$ for ecological public welfare forest and 0.450 ha $(6.957 \mathrm{Mu})$ for merchantable timber. The main species are Masson's pines (Pinus massoniana Lamb.) and China firs (Cunninghamia lanceolata (Lamb.) Hook). The area for Moso bamboo (Phyllostachys edulis (Carrière) J. Houz.) is about $13.333 \mathrm{ha}(200 \mathrm{Mu})$. The main crop of Shanlian Village is rice. The scale of animal husbandry is small. The main livestock is goats, and the total number is 60 . The mean number of input-output per unit is 1:3. The main activities of forestry production in Shanlian Village are shown in Table 1.

In this survey, publicity, training, participatory interviews, brainstorming, and 


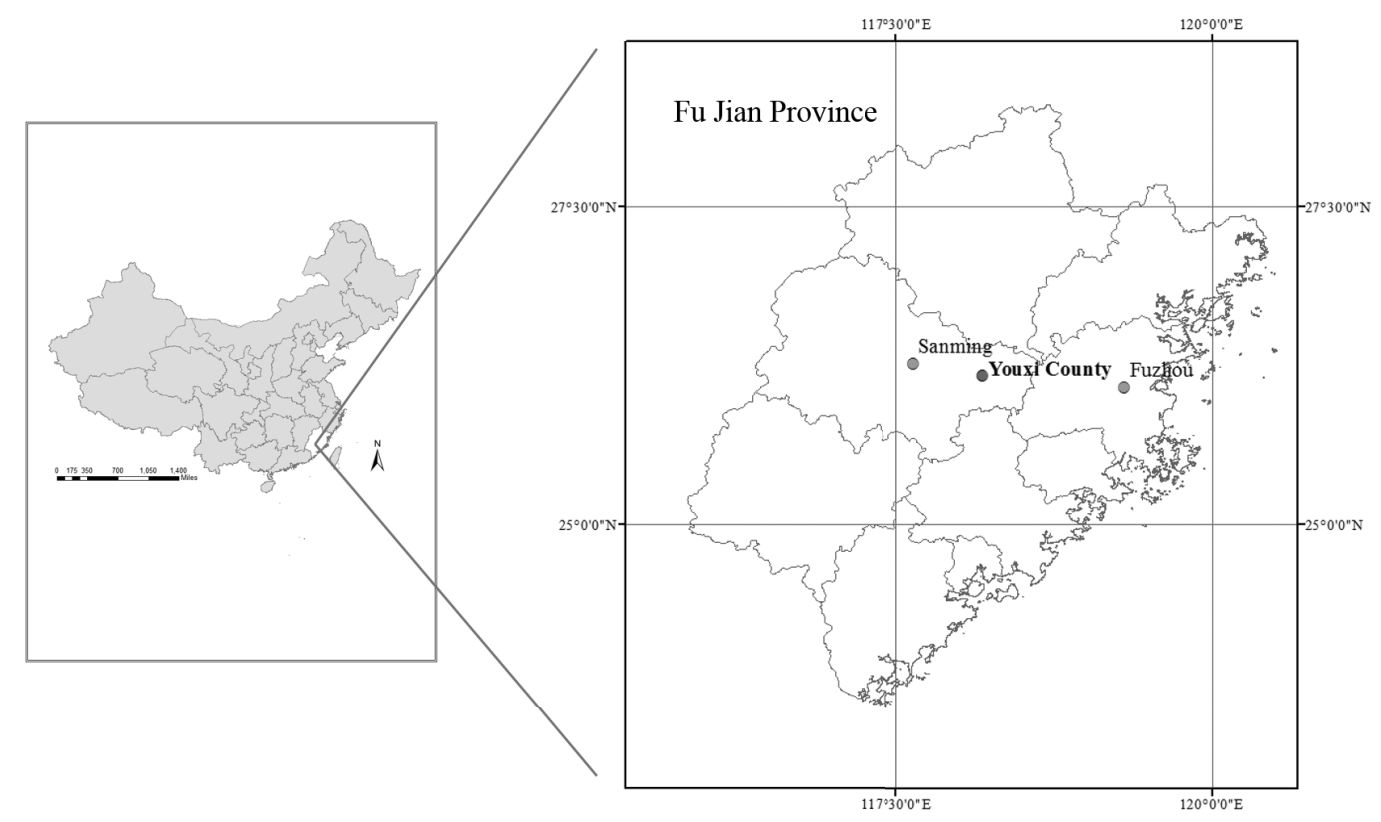

Figure 1 . The map of study area.

Table 1. The main activities of forestry production in Shanlian Village.

\begin{tabular}{cccc}
\hline Activities & Scale & Income (Yuan) & Expenses (Yuan) \\
\hline Timber & Private Processing Factory & 600000 & 350000 \\
Bamboo & 40 000 Moso bamboo stems & 80000 & 45000 \\
Dried bamboo shoots & 2000 kilograms & 30000 & 15000 \\
Wet bamboo shoots & 4000 kilograms & 8000 & 4000 \\
Fruits & $\begin{array}{c}2 \text { ha (30 Mu) oranges } \\
\text { (Citrus sinensis (L.) Osbeck) }\end{array}$ & 30000 & 18000 \\
\hline
\end{tabular}

questionnaire surveys were used. The stakeholders involved in this project are mainly the owners of the forest (members of the forestry cooperation organizations), village leaders, the leaders of cooperative organizations, and local government officials.

The survey group chose 20 to 30 individuals (of which 15-20 are cooperative members and 5-10 are non-members) in the case county and village as the subjects of publicity and training, which include a detailed introduction to the current laws and policies for the development of forest farmer cooperatives.

After the training, the survey group organized interviews with forest farmers and with forestry workers, in which partici- 
patory tools like brainstorming were used and key questions raised, and interviewees were guided to discuss issues actively and propose suggestions.

We used the brainstorming method through open-ended questions, making each forester attending the training write down his own views. These open-ended questions addressed functions and development problems of the cooperative organization; improvement needed for the internal management of the cooperative organization; and existing problems with the cooperative organization guide and suggestions for improvement. By thinking about and answering these questions, foresters developed a clearer understanding of their own needs as well as the reality of the existing problems of the cooperative organization. At the same time, being exposed to the interpretation and analysis of experts on the issue gave foresters a more profound understanding of farmers' cooperatives.

\section{Results and Discussion}

\section{Cooperatives in the case area}

Lvyuan Forestry Cooperative is located in Shanlian Village, Xicheng Town, Youxi County in Fujian Province. It is approximately $24 \mathrm{~km}$ from the town and was founded in October 2007. The operation mode of the cooperative involves stocks, with independent business accounting and full responsibility for profits and losses. It adheres to the principles of a marketing operation, maintaining the value of assets and sharing the risks and interest. The main businesses of the cooperative include the cultivation of forest resources, the management of forest assets, cutting wood, and the sales of forest products. At present, the business area is about $40.93 \mathrm{ha}(614 \mathrm{Mu})$.

To raise funds for the cooperative, the Members Representative Assembly estimates the reforestation expenses every year, and divides the total amount by the population of the village that has right to buy stocks. Each family participates using its purchased stocks, and the stocks can be transferred among the villagers. The Village Committee participates by holding forestland stock. The stock is made up of $70 \%$ villager stocks, and 30\% forestland stocks. At the end of the year, the total value of fixed assets was 1.2 million yuan, and the operation and service expenses for the whole year were 18.000 yuan. At present, the cooperative is not making a profit. The main business of the cooperative is production activities related to the cultivation of forests. Table 2 introduces the development of the cooperative.

The institutions of the cooperative include the Members Representative Assembly, the board of directors, and the board of supervisors. The Members Representative Assembly is the highest authority of the cooperative, and it is made up of 1-2 representatives from each villager group after democratic consultation. There is at least one meeting of the Members Representative Assembly every year, and it is organized by the board of directors. The board of directors is the executive body of the cooperative, and it is responsible for the Members Representative Assembly. The board of directors is made up of four members: the director, the deputy director, and two members. The board of supervisors is the supervisory body of the cooperative, and supervises the board of directors and the other staff in the name of all members. There are five members of the board of supervisors, including one chairman, who can attend the meetings of the board of directors. The governance structure of the cooperative is detailed in Figure 2.

\section{Basic information for the survey sample}

The basic information about and characteristics of the people participating in the training and interview in Shanlian village are as follows. All the people in Shanlian village, Xicheng town, Youxi county participated in the Lvyuan Forestry Cooperative, 
Table 2. The introduction to the development of the Lvyuan Forestry Cooperative.

\begin{tabular}{cccc}
\hline & 2007 & 2008 & 2009 \\
\hline Numbers of Members & 1003 & 1090 & 1103 \\
Numbers of Families & 207 & 207 & 210 \\
Assets & 200000 & 500000 & 750000 \\
Main Species & China fir & China fir, Masson's pine & China fir, Masson's pine \\
Annual Profit & 0 & 0 & 0 \\
\hline
\end{tabular}

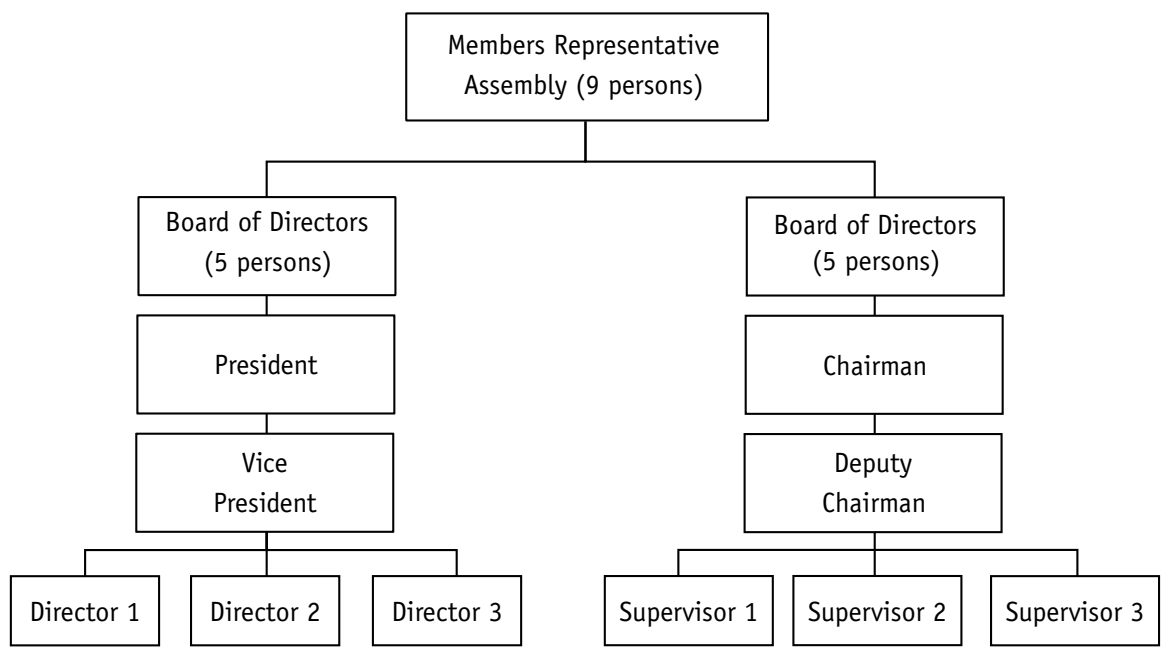

Figure 2. The Governance Structure of Lvyuan Forestry Cooperative in Shanlian Village.

so all of the research objects were members of the cooperative organization, for a total of 21 people, including two village cadres, one head of the cooperative organization, and one staff member of the township forestry station. The basic characteristics of the survey objects selected from the sample villages are as follows. There were two women among the 21 respondents; the average age was 48 , and there were nine people aged $40-50$ years, representing the largest age segment (43\%); and the education level of the respondents participating in the discussion was higher than the average level of the village, with $50 \%$ having finished junior high school or a higher level of education. The average number of people in a household was four. Excluding the cooperative organization woodland, the average area of the forestland was 1.212 ha ( 3 acres).

Eight staff from the Youxi Forestry Bureau participated in the discussion forum for the department in charge of forestry, including the deputy party secretary of the Forestry Bureau, the director of the office, the director of the Forestry Reform Office, the head of the Xicheng Forestry Station, the director of the technology center, senior engineers for forestry, and the director of the service center for forest rights. All eight participants had finished college or 
a higher level of education, and they had engaged in forestry work for 13 years on average.

\section{Problems in the development of Lvyuan Forestry Cooperative}

Through interviews with key personnel, we found that currently the main problems affecting the future development of the Lvyuan Forestry Cooperative hinge on the following. First, because of the long cycle of forestry production, the cooperatives paid great attention to the current investment, and at the same time, the government focused on the ecological construction of recent years, restricting the use of the forest resources, so that the foresters lost some of the benefit, and the cooperative was not yet profitable. Second, the management structure of the cooperative was relatively simple, mainly involving the management of bamboo and fir, which limited the development of other products for the forestry economy. Third, the cooperatives lacked of support of talent, since increasing numbers of young people were becoming city workers, and the relevant technical training to improve the level of forest management was not sufficient, so the competitiveness of the cooperatives needed to be improved. Fourth, after the southern collective forest was distributed to the households, the woodland rights were scattered, and it was difficult for the cooperatives to practice large-scale woodland management.

\section{Households' needs and problems in the development of cooperatives}

Of the people surveyed, $94.6 \%$ thought it was necessary to set up cooperative organizations for the foresters in the village, and only $5.4 \%$ believed there was no need to do so. Through brainstorming and letting forest owners discuss their own views, it was reveled that they believed the greatest current development needs for the cooperative organization were to obtain economic benefits, policy support, and technical training. Foresters who were investigated said although the whole village had joined the Lvyuan Forestry Cooperative and invested in forestry management annually, the planted fir had not yet become a forest because of the long forestry production cycle, so there was no income thus far. Therefore, the most urgent needs of foresters were to get government policy support, access technical training, implement innovative forestry management methods, introduce a new business philosophy, and increase their economic benefits. In addition, the foresters also proposed other cooperative organization needs, such as protecting the environment to ensure ongoing survival, and getting initial forestry funding for farmers' production management (Figure 3).

The survey showed that the Lvyuan Forestry Cooperative in Shanlian village was mainly confronted with the following problems (Figure 4). First, there was a lack of financial support for the development of the forestry cooperative. The forestry cooperative was in the investment stage, and had not been profitable thus far. Second, there was not enough supervision of the cooperative. Although villagers in Shanlian village participated in the cooperative, the whole organization and management of it was not standardized, and it lacked clear oversight of management and a monitoring approach. Third, there was a lack of practical technical training in forest management. Fourth, there was a lack of leaders. Although there were relevant staff in charge of the cooperative, there were still not enough people leading the foresters to develop the forestry production and increase the forest income. Chinese cooperative organizations were a relatively recent development, so members did not have much awareness of cooperation; their ability to fulfill their duties was relatively low. Therefore, in the development of the cooperative organization, there was always a key figure leading the direction, while the general members did not know they also 


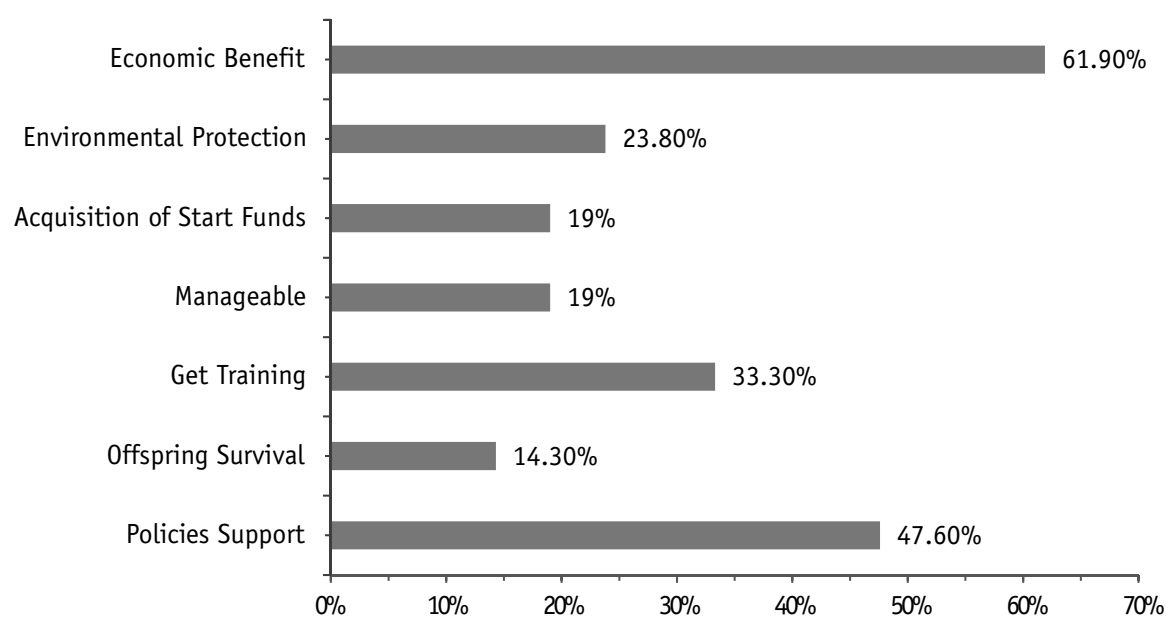

Figure 3. Households' Requirement in the Development of Cooperatives.

had rights and responsibilities, so that the cooperative organization was difficult to operate.

The real driving force for the development of the cooperative organization itself was people's demand, which came from people asking for forestry management benefits (Zhang et al., 2007). This study presents the results that the cooperative organization was established (1) because the forestry production and operations encountered problems such as lack of capital, technology, market information, or labor, which required everyone to cooperate to solve the problems (Yang et al., 2013), and (2) to pursue some benefit in the forest management process. Foresters' personal operating cost was high, while their income was low, and only by cooperating could they reduce costs and increase income. It was obvious that the driving force to establish the cooperatives was the pursuit of benefit, and the source of benefit was to increase productivity, reduce costs, and solve problems. If the driving force was not clear, the development of the cooperative organization required more policy guidance and protection, strengthening its development and demonstration. At present, the forestry cooperative organization's development is still in its infancy. Forestry has its own particularities: the production cycle is long, the degree of intensity is low, and it is more dispersed in terms of resource use and production and operation time, so cooperation is an important way to solve real-world problems.

\section{Forestry workers' opinions on the development of forest farmer Cooperatives}

During the interviews, forestry workers identified several advantages of developing cooperatives. In the collective forest areas in South China, after the forests were allotted to households in the forest tenure reform, the household-run pattern increased the cost of forestry production and lowered the forest land's ability to resist risks, which is not in favor of the scaled forest land management and effective forest resource allocation. However, cooperatives can centralize the scattered resources, achieve economies of scale, lower costs, and enhance the forestland's ability to withstand risks. Cooperatives represent an important economic organization pattern for future forestry production and operations. The ultimate goals of promoting COoperatives in collective forest areas are to 


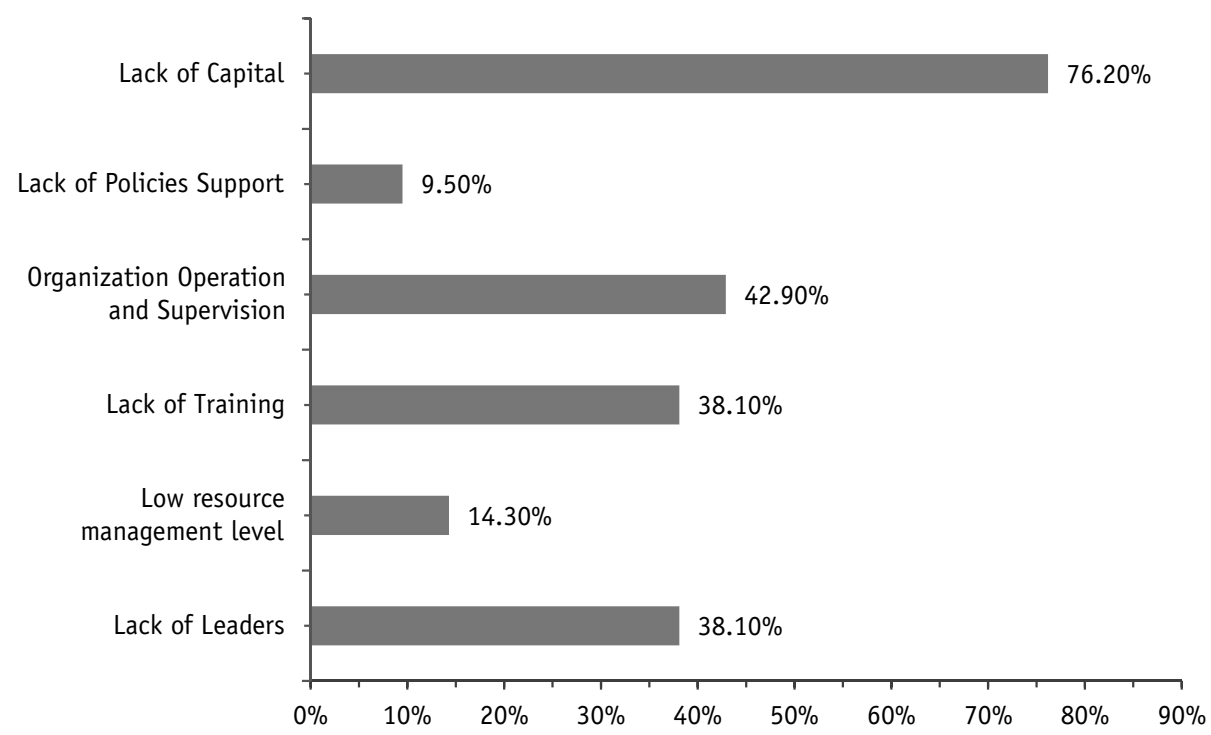

Figure 4. Existing problems in the development of cooperatives.

create profits for forest farmers and to contribute to the realization of the three major benefits of forestry.

After the forest tenure reform in 2003, forest farmers could not only invest more in forestry but also gained more confidence for forestry operations after clarifying forest ownership. The various favorable policies put forward by the government also contributed to the establishment of a large number of cooperatives. The present forestry policy system lacks long-term planning. For example, the tenure of forestland is generally 30-70 years, but after the reform, parts of the forest area will be adjusted every 15 years. Thus, the farmers can only benefit from first-generation forests. Since the production circle of forests is relatively long and a reallocation will be carried out after the first-generation trees are cut, forest farmers lack long-term awareness and ignore the long-term benefits of cooperatives.

In addition, the country has paid increasing attention to ecological benefits in recent years, so the polices are more oriented toward ecological construction. It is forest farmers who pay the price for ecological construction, although the whole nation enjoys the ecological benefits. Ecological construction projects have limited the economic benefits of forestry and impaired forest farmers' economic interests. Currently, the compensation for ecological forests constructed for the public welfare is 12 yuan per $\mathrm{Mu}$ (0.067 ha), which is far from enough for forest farmers. Hence, in terms of the overall environment, the current policy environment restricts the cooperatives' development to some extent. Chinese national law for farmers' cooperatives gives more attention to the cooperative organizations formed in the agricultural and related industries involving agricultural and livestock production activities than to the contracting and management of woodlands. There are some differences between forestry and agriculture and animal husbandry. For example, a mortgage can be taken out on woodlands, but not on agricultural land; and the agricultural production cycle is one year or six months, whereas the forestry production cycle is decades or even longer. Therefore, farm- 
ers' needs for the elements, land, market, and technology, as well as their desire for cooperation and the appropriate forms of cooperation are diverse, and the realization of benefits is short-term. Therefore, the Cooperative Organizations Act could not cover the basic characteristics of the forestry and foresters' cooperative organizations, leading to a lack of effective legal support and protection in the development of these organizations.

At present in China, there are many preferential policies for the establishment of specialized forest farmer cooperatives. The forestry workers interviewed regard these preferential policies as the key reason for the quickly growing number of cooperatives. However, the surveyed forestry workers point out that although the number of cooperatives is increasing rapidly, the original goals of the cooperatives have not been achieved, and the development of cooperatives is still very slow. The main reason for this is that the development process of cooperatives is rather onesided. The existing cooperatives mainly deal with forest products like timber and bamboo, while those cooperatives mainly engaged in producing flowers and seeds and under-tree growing and breeding are very difficult to have approved. Further, the cooperatives that can really realize economic benefits and benefits of scale are very difficult develop. The business scope of cooperatives should be broadened in the future to enable them to develop in a more diversified way.

From the forestry workers' point of view, if there were no effective policies, such as ecological compensation for public welfare multi-purpose operations and management, or a change in the business model, then the policies would constrain the development and implementation of cooperative organizations. If there were no policy in place, then the development of cooperative organizations would inevitably be affected. The main object of forestry production and business activities is the exploitation of forest resources, which are not only a kind of economic resource but also a kind of ecological and public welfare resource, as timber has ecological functions. The national policy is not just to encourage the development of forestry and the use of forest resources to help farmers gain more income. It also aimed at achieving cohesiveness of the forest ecosystem, better protecting national ecological security, enhancing the quality of the forest ecosystem through relevant protection policies such as limited harvesting, and constructing an ecological and public welfare forest. In response to climate change and desire for a low-carbon society, the ecological and social service functions of forest resources have gained increasing attention, which was bound to lead to the process of cooperation in the operation of cooperative organizations and the realization of benefit being constrained and influenced by national policies.

In this study, forestry workers also held the view that the cooperative organizations mainly focused on the following items that greatly influenced production activities: short production cycle, high commercialization and technical content, large amount of input factors, marketing, the economy of the forest, tea, and so on. The cooperatives formed in consideration of these aspects would achieve better development. When cooperative organizations focus on forest resources such as timber to address members' expectations of benefit, the difficulty of securing direct operating income in the short term affects the development of the cooperative organizations (Yang et al., 2013).

\section{Conclusions}

Through brainstorming, group meetings, semi-structured interviews, and other forms of gathering opinions from different stakeholders, we can conclude that the relevant supporting policies should be 
strengthened to ensure the normal operation of the cooperative organizations. All aspects, including the cooperative organizations' management, the protection of the members' interests and rights, and supervision require relevant policies and regulations as well as the cooperation and coordination of the departments of industry and commerce, taxation, and so on. Therefore, we should develop these policies considering all aspects of tax concessions, ecological compensation, forest tenure mortgages, and felling quota. Cooperative organizations undergo a long process of development. With the upgraded level of economic development in the national market, the continuous improvement of the national system and policy environment, and the continuous improvement of farmers' awareness and ability, cooperative organizations have developed rapidly and well. In this case, the forestry department in charge of the development of the relevant cooperative organization gave more attention to creating a favorable environment for development, promoting the development of the forestry cooperative organization gradually and progressively.

According to households' needs and forestry workers' opinions as well as the problems existing in the Lvyuan Forestry Cooperative, the concrete suggestions for the development of the current cooperative organizations are as follows: First, the relevant laws and guarantee systems for resource exploitation and management should be made in accordance with the forest farmers or the forestry cooperatives. For example, the policies concerning social services, the system guarantee, and interest compensation should provide a fundamental legal guarantee of the future development of the cooperatives. Second, the cooperatives should be developed based on the practical demands of the forest farmers rather than the demands of the government, as the fundamental motivation for the development of the cooperatives is to pursue the farmers' interests. Through publicity and policy guidance, we could promote the sound development of some normative and profitable cooperatives to promote their guiding and demonstrating functions rather than develop the cooperatives in a mandatory way. Third, through forestry technology training, especially skills training for the cooperative and its members, the forest farmers will be provided with better external and fundamental conditions to join the cooperatives. The contents of the training should include basic knowledge of the cooperative, the relevant laws and supporting policies, and practical forestry skills. Finally, the government should adopt an effective mechanism to overcome and address the specific problems existing in the development process of the cooperatives. The department in charge of forestry should give more attention to guiding, demonstrating, guaranteeing, and enhancing a sound development environment to promote cooperative development.

Acknowledgements. This article was financially supported by the national forestry public welfare industry scientific research subject "Form a complete set of supporting technology and security system integration and demonstration in Sanming forest experimental zone in Fujian Province" (201004008).

\section{References}

Nie, H. 1995. External effects of forestry economy. Journal of Beijing Forestry University, 17, 88-92. (In Chinese).

Xie, H.S., Li, Z.Y. 2010. A review on forest famers cooperative organization in the context of collective forest tenure reform. - Forestry Economics, 12, 35-39. (In Chinese).

Yang, L., Wen, Y., Aguilar, F.X. 2013. Nonindustrial family forest landowners' stated willingness-toparticipate in forest cooperatives in Southern China. - International Journal of Forestry Research, $12,1-12$.

Zhan, L.F. 2010. Empirical research on the impact factors of farmers' afforestation investment: a case study of rural household in Fujian Province. - Issues of Forestry Economics, 30, 322-325. (In Chinese). 
Zhang, D., Ding, L., Xia, H. 2007. Analysis on the farmers' desire to join in farmers' specialized cooperative organization based on the logistic model. - Journal of Henan Agricultural University, 3, 33-341. (In Chinese).

Zhang, H., Zhang, Z.G. 2009. Game behavior analysis about construction and development of forestry cooperation organization. China Population. Resources and Environment, 22, 107-111.

Zhang, J., Zhi, L. 2010. Current situation and prospect of forestry cooperative economic organization. World Forestry Research, 23, 65-68. (In Chinese).

Received March 15, 2014, revised May 5, 2014, accepted November 24, 2014 